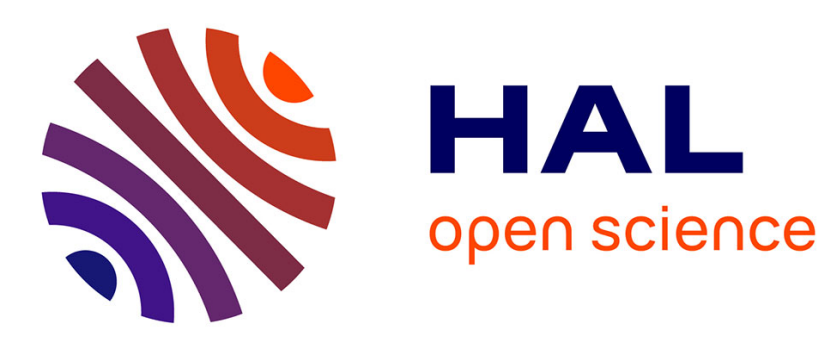

\title{
A mechatronic conception of a new intelligent braking system
}

Gérard Gissinger, Christian Menard, Alain Constans

\section{To cite this version:}

Gérard Gissinger, Christian Menard, Alain Constans. A mechatronic conception of a new intelligent braking system. Control Engineering Practice, 2003, 11 (-), pp.163-170. 10.1016/S09670661(02)00041-2 . hal-00962314

\section{HAL Id: hal-00962314 https://hal.science/hal-00962314}

Submitted on 21 Mar 2014

HAL is a multi-disciplinary open access archive for the deposit and dissemination of scientific research documents, whether they are published or not. The documents may come from teaching and research institutions in France or abroad, or from public or private research centers.
L'archive ouverte pluridisciplinaire HAL, est destinée au dépôt et à la diffusion de documents scientifiques de niveau recherche, publiés ou non, émanant des établissements d'enseignement et de recherche français ou étrangers, des laboratoires publics ou privés. 


\title{
A mechatronic conception of a new intelligent braking system
}

\author{
G.L. Gissinger ${ }^{\mathrm{a}, *}$, C. Menard ${ }^{\mathrm{b}}$, A. Constans ${ }^{\mathrm{b}}$ \\ ${ }^{a}$ Laboratoire MIAMIESSAIM, University of Mulhouse, 12 rue des frères Lumière, 68093 Mulhouse Cedex, France \\ ${ }^{\mathrm{b}}$ Newtech; Blainville, 779, Industriel Boulevard, Quebec, Canada J7C3V3
}

Received 19 October 2001; accepted 17 January 2002

\begin{abstract}
This paper describes a new intelligent braking system for motor vehicles. A mechatronic approach helped to avoid some of the drawbacks found in conventional systems. The brake was designed according to the so-called "full contact disc brake" principle, which means that the classic pads are replaced by the whole discs and that - for maximum performance - the brake is controlled continuously and not cyclically as with classic ABS systems. This required a complete re-design of the regulation chain, the actuators and sensors. Indeed, to provide better control, the regulator uses feedback information not only from slip, but also from the braking torque. (C) 2003 Published by Elsevier Science Ltd.
\end{abstract}

Keywords: Braking system; Automotive control; Mechatronics

\section{Introduction}

ABS braking systems have been well-known in the automotive industry for many years. At first, they were optional extras for upmarket vehicles, then became more "democratic" as part of the basic equipment of most vehicles. Several generations of such systems have followed one another and now they are considered perfect by the general public and so need not, or cannot, be improved. Yet, a generalized conception (Richalet, 1991) or a mechatronic approach (Isermann, 1996), i.e. a reflection on all the principles, components, sensors, actuators, regulation, etc., can lead to important improvements in these fields, as in others.

It must be repeated here that current regulated braking systems work through cyclic pressure decreases and increases in the brake, so that slip $g$ stays within the stable part of the curve that represents grip according to slip $g$. The shape and amplitude of this curve, called Pacejka's curve, are parametrized by the nature of the road surface. Grip is defined as the ratio between the horizontal force (which can be transmitted by the tyre) and the vertical load (supported by this tyre). Grip is defined by

$g=\left(V_{\mathrm{v}}-V_{\mathrm{s}}\right) / V_{\mathrm{v}}$,

*Corresponding author. Fax: +33-389-33-69-49.

E-mail address: g.gissinger@uha.fr (G.L. Gissinger). where $V_{\mathrm{v}}$ is the speed at the wheel/road contact point and $V_{\mathrm{s}}$ is the real wheel speed, $V_{\mathrm{s}}=r \omega$.

Hence grip $=0$ when the wheel is unlocked, and grip $=1$ when the wheel is locked. Fig. 1 shows the shape of the so-called Pacejka curve (Pacejka \& Sharp, 1991) for different road surfaces. It must be noted in particular that the maxima of the curve change for both grip and slip when the road conditions change.

The aim of the regulation of the braking system is then to hold the functioning point as close as possible to the maximum of the curve. Any functioning at a lower point leads to a loss in efficiency; any functioning beyond the maximum causes the wheel to lock, which also leads to a loss in efficiency. This shows the importance of the temporal notion and explains why a cyclic principle will mostly be the source of a waste of time and so, of efficiency.

Therefore, the fundamental idea of the intelligent braking system (IBS) was to find a way to avoid the different drawbacks of regulated braking systems. To reach this goal, all the components have been questioned and re-designed accordingly.

\section{General principle of IBS}

To avoid or limit the problems of reliability of operating temperature in case of intensive use (in 


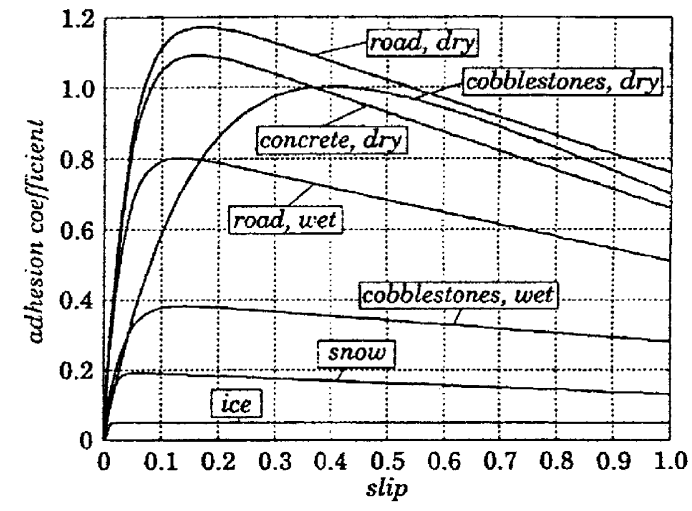

Fig. 1. Pacejka's longitudinal model of the tyre.

particular for heavy vehicles and their trailers), of life time, residual friction, noise, vibrations, a new brake has been designed according to a modular principle which helps to group together the brake, the suspension, the wheel and its bearing into one set. So, final assembling becomes easier. The regulator works on the basis of a control loop of slip and torque. A specific sensor has been developed to measure this braking torque. On principle, the actuator must be a continuous one or a proportional electrovalve and the first results were obtained with specific servovalves and with others available in the market. Most components were entirely designed using CAD before they were manufactured or implemented, which saved much time and money. Fig. 2 shows the general architecture of IBS. It must be noted that this version is based on the hydraulic control of the brake. An all-electric version is currently being studied, along with others developed with new materials. The prototypes are developed for different major car-manufacturers.

A test bench was specially designed and built for the application; it helps to confirm the theoretical investigations and then to obtain the first results before their implementation in test vehicles. Fig. 3 shows an overall view of the test bench which allows the validation of a four-wheel braking system, by taking account of the real load transfers during braking.

\subsection{The brake}

Essentially, the new brake consists of two annular pads: an "outboard pad" and an "inboard pad". When the brakes are applied, these pads grip the entire surface of the rotor, thus distributing pressure over $360^{\circ}$ for maximum friction area. An aluminium driving hub connects the brake system to the wheel as well as provides easy access to the hub carrier. Polymeric inserts located on the hub keep the rotor suspended while absorbing shocks. The rotor, made of a metallic composite, literally floats on the driving hub through the polymeric inserts. This special design not only

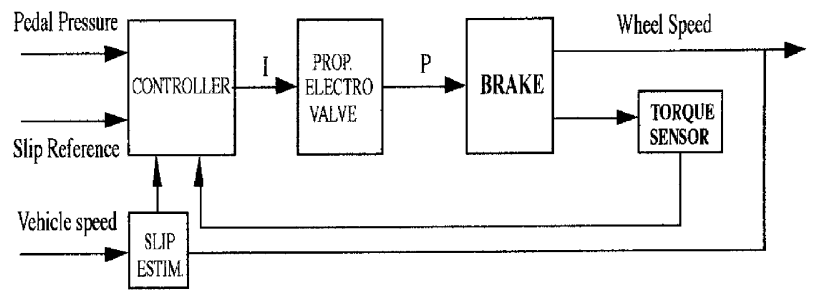

Fig. 2. General architecture of IBS.

eliminates all noise caused by resonating parts, but also helps ventilate the brake and dissipate heat through the cavities and fins on the rotor surface.

Performance expectations for the new brake include improvements in noise, vibration and harshness based on:

- A floating rotor which utilizes seals in the driving hub to optimize rotor position effectively eliminating system drag.

- Uniform rotor wear $\left(360^{\circ}\right)$ which eliminates the harshness associated with caliper system runout and extends the life of friction materials and rotors.

- Uniform pressure at engagement and increased clearance between the rotor and friction material which minimizes noise, vibration and harshness.

- Finite element analysis studies that confirm low foundation operating temperatures minimizing rotor deformation while increasing the life of all system components.

Fig. 4 shows the full contact disc brake:

(1) The housing, made of aluminium, has been designed to optimize the use of space inside the wheel. It holds the outboard pad and supports the whole brake assembly.

(2-3-4) The spider and the hub carrier have been combined to integrate the brake system and the suspension. The spider is equipped with a torque sensor that transmits the torque exerted on the brake.

(5-6-7-8) The inboard (6) and outboard (5) pads, located on each side of the rotor (7), also have fins for further dissipation of heat. The inboard pad is fitted with a moulded thermal barrier made of a special composite material. Special inserts made of friction material are distributed evenly on the entire surface of both pads. Various friction materials are combined to ensure performance under diverse conditions. When the brakes are released, the inboard pad is returned to its original position by means of a special spring-loaded mechanism. The rotor then disengages from the outboard pad and returns to its neutral position.

(9) The hydraulic diaphragm - a membrane made of an elastomer composite-is incorporated into the 


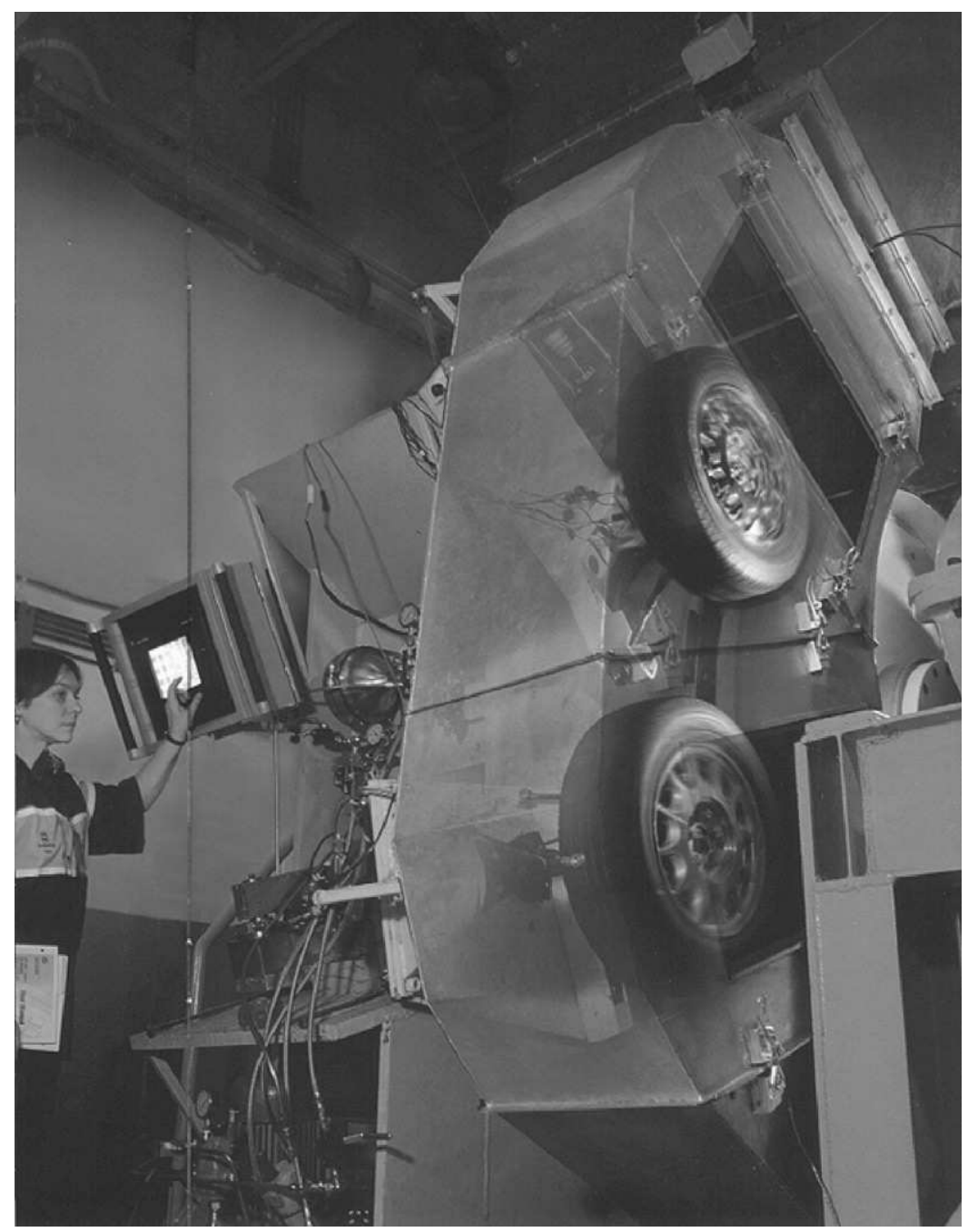

Fig. 3. NewTech's four-wheel test bench.

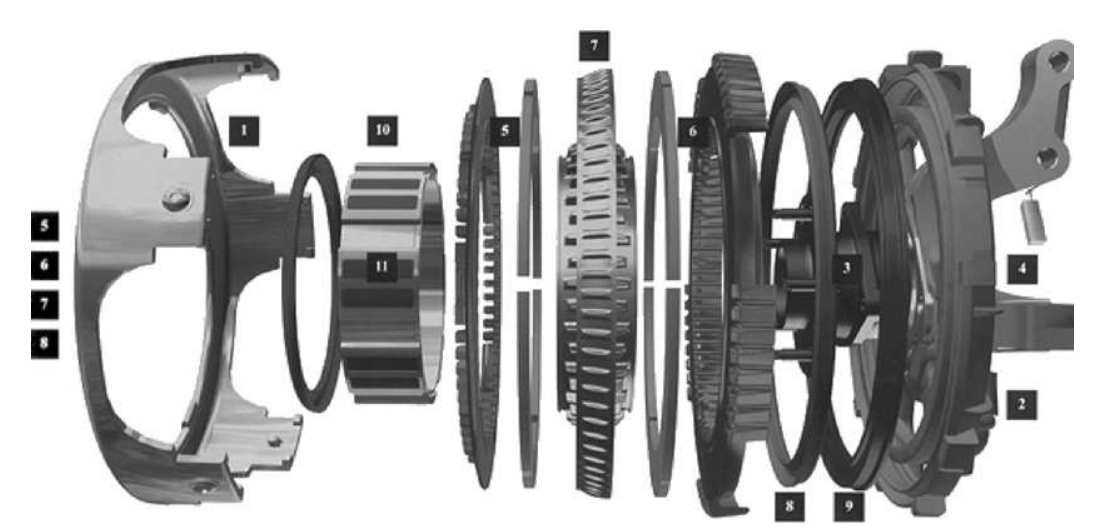

Fig. 4. The full contact disc brake.

spider. It extends and retracts much like a piston. Incredibly resistant, it can withstand 15 times the required pressure. Besides providing a rapid and gradual action during braking, it needs little pressure to operate the action. This diaphragm is kept in position inside the spider by means of a "gasket-ring" which eliminates distortion and leaks that could occur through excessive use of brake. 
(10-11) The rotor is connected to the wheel by means of the driving hub. It is kept in optimal working position at all times by the polymeric inserts. When the brakes are applied, hydraulic pressure extends the diaphragm, which in turn exerts pressure on the inboard pad. This forces the rotor against the outboard pad: the rotor is thus gripped on its entire surface, between the two pads. When the brakes are released, the diaphragm retracts and the spring-loaded mechanism returns the inboard pad to its original position, thereby releasing the rotor which can start rotating again. Through its continual progressive action, the diaphragm constantly compensates for the wear in the thickness of the pads resulting from friction. The parking brake is incorporated into the driving hub of the rear wheel.

This brake design offers significant packaging improvements over traditional disc brake systems.

- The NewTech modular configuration eliminates the over hanging caliper.

- The one-piece assembly also simplifies the concept of unified brake/suspension installation.

- Containment of the rotor in the housing will reduce the level of friction dust reaching the wheel.

- Full contact over $360^{\circ}$ ensures a braking surface up to 7 times greater than that of conventional brakes. This distributes the heat energy released during braking more evenly, thereby reducing thermal constraints and wear, as well as the risk of losing control of the vehicle.

- Because the position of the rotor is constantly optimized in relation to the brake pads, full contact over $360^{\circ}$ is assured. Therefore, there is less noise and less vibration, which means lower costs associated with the manufacturer's guarantee.

- The low pressure exerted on the pads by this type of brake eliminates the need of a back-up braking system thereby significantly reducing the costs of braking systems.

- Plastic master cylinders could replace cast cylinders due to reduced system pressures.

- Cost saving opportunities proliferate in the applied system as lower required system operating pressures allow downsizing and elimination of many system components.

\subsection{The sensors}

A previous study (Chamaillard, Gissinger, \& Menard, 1994; Gissinger, Voit, \& Chamaillard, 1996) showed that some of the limitations with current systems were due to the fact that no information on the internal working of the brake was taken into account. It also showed that the dynamic measurement of the braking torque helped to determine an internal variable of the system and to eliminate some problems of controlability. A specific sensor was then developed (Perronne, Renner, \& Gissinger, 1994).

According to the origin of the strain of the structure on which this sensor is mounted, it can measure forces, weights, torque, accelerations, etc. The geometry of the sensor has been designed to give the sensing element a pre-stressing set-up and a small stress at the locating points. This sensor is based on a method of strain analysis. It delivers an electrical signal ranging from 0 to $4.5 \mathrm{~V}$ proportional to the displacement of the locating points (microdeformations), and thus to the strain of the structure. Due to the small dimensions and easy setting up, this sensor of versatile use can be adapted to and integrated into existing processes.

The displacement measuring range is $32 \mu \mathrm{m}$ plotted to the ends of the sensitive component, which corresponds to a $1,250 \mu \mathrm{m} / \mathrm{m}$ deformation. Sensitivity is $100 \mathrm{mV} / \mu \mathrm{m}$, linearity is better than $2 \%$ and hysteresis better than $1.5 \%$. Different ways of fixing the sensor are possible, but two types of gluing are recommended: rapid test gluing for a try with a glue of the cyano-acrylate type or permanent gluing with a high resistance epoxy glue. There are temperature self-compensating versions for steel and aluminium supports.

Zero adjustment point is set up on site and held in position by an alignment template. After the glue has properly dried, this alignment template is broken or removed and the sensor is immediately operational.

Fig. 5 shows the sensor and Fig. 6 shows its calibration curve.

\subsection{The actuator}

As mentioned previously, the actuator must on principle allow continuous brake control. The first tests

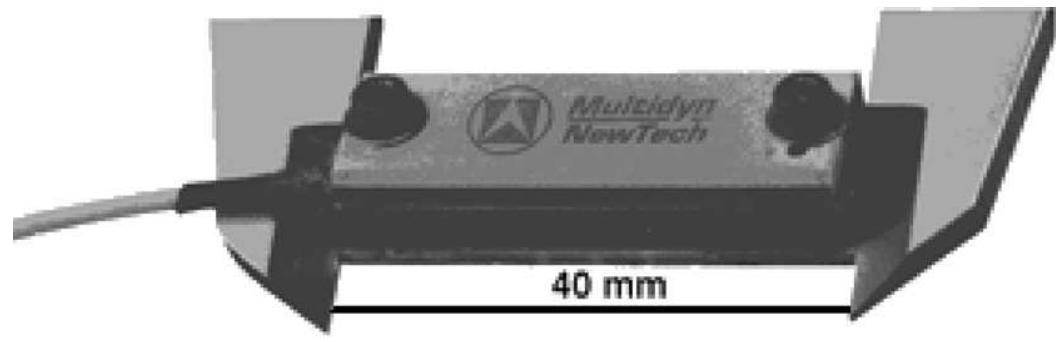

Fig. 5. NewTech's Mechatronic Sensor. 


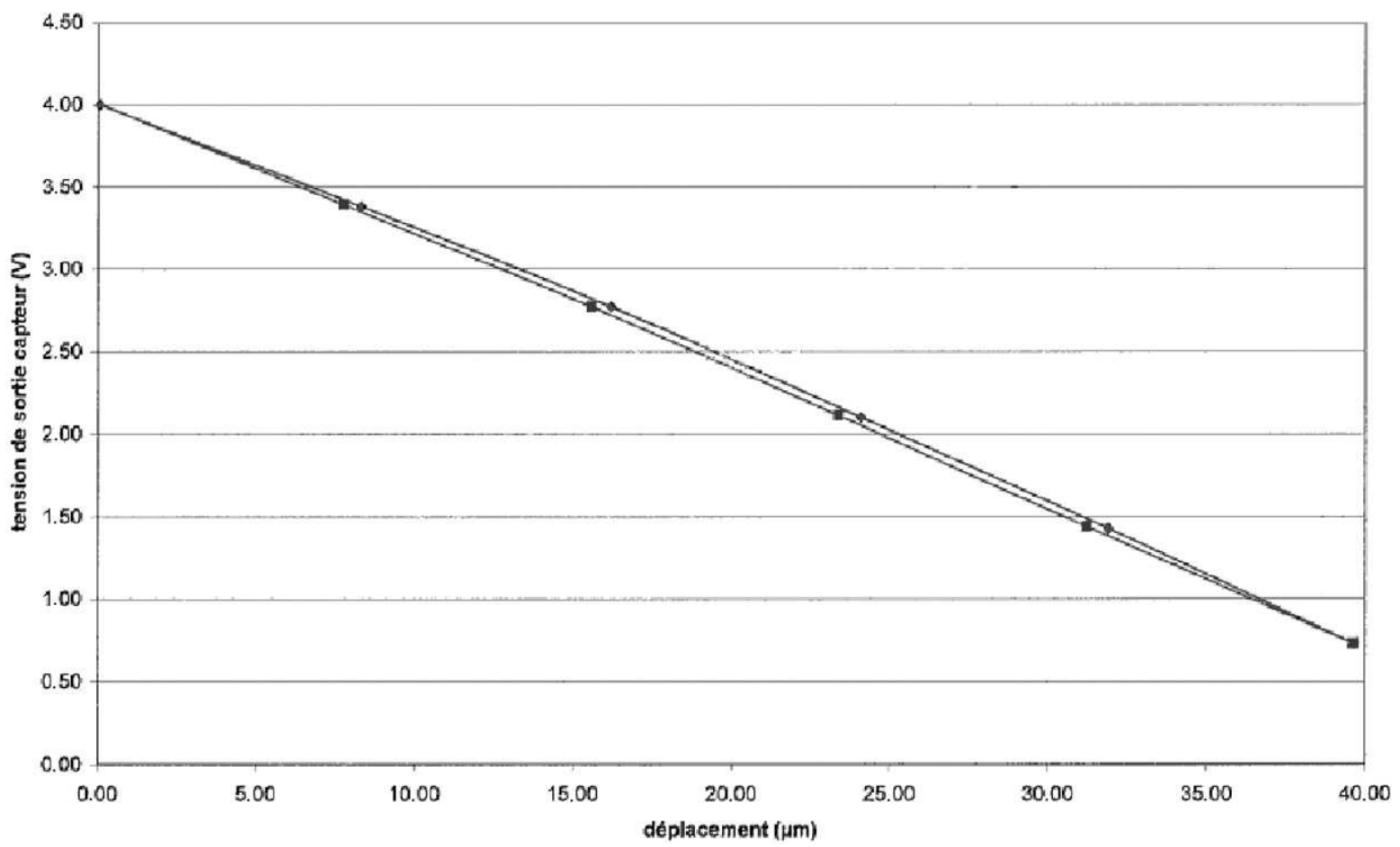

Fig. 6. Calibration curve of the torque sensor.

were carried out successfully thanks to a proportional servovalve (Stemmelen, Gissinger, \& Menard, 1996) that allowed the direct control of the pressure or flow of the fluid through an input current $(4-20 \mathrm{~mA})$. The bandwidth of the servovalve must meet the required performance, but then the system becomes relatively expensive, which is the case at the present time.

Promising results were obtained with a proportional electromagnetic valve - available in the market and currently used in the automotive industry, which means at a reasonable price for manufacturers. The hydraulic fluid can be a classic brake fluid (ATF Dextron 2 or 3); here again, several other tests were carried out and gave good results. As the pressures in the brake are relatively low, no particular precautions need to be taken. Studies for the design and development of an electric actuator are currently underway. Depending on the architecture of the hydraulic system on the car, the bandwidth of the whole braking system is $7-10 \mathrm{~Hz}$.

\subsection{Control}

\subsubsection{Material means}

The core of the system consists of an electronic control box which collects the data from the different sensors and commands the different actuators. This box includes:

- a 16-bit $20 \mathrm{MHz}$ microcontroller with 256 ko Flash memory,

- a 10-bit, 16-input CAN, 4 MLI outputs,
- a filtered protected input/output card including:

- 1 input for the brake pedal reference

$0 \quad 1$ input for the steering wheel position

- 4 inputs for the tachometric sensors

- 4 inputs for the torque sensors

- 3 input for the accelerometers

$\circ \quad 1$ input for the gyrometer

$\circ 4$ logic inputs

- 4 current outputs 4-20 mA

- 4 MLI power outputs

$\circ 1$ relay output.

\subsubsection{Software development}

The electronic command box defines the output state according to the inputs thanks to a specific software programme developed by the laboratory team. This programme is written in $\mathrm{C}$ language in a structured, upgradeable, optimized way: the first layer performs the basic functions (inputs/outputs in particular), the next layers perform high-level functions such as the calculation of the speed, the regulation loops of the braking torque and slip, the regulation loops of the complete vehicle's behaviour (of the anti-yaw type, etc). The whole system can be parametrized and tested using specific functions.

The vehicle speed can be reconstructed from its longitudinal and transverse components (Porcel, Runde, Basset, \& Gissinger, 1998). A fuzzy estimator calculates the longitudinal component from the four wheelspeeds and from corrections based on the transverse 
acceleration and the yaw rate. As for the transverse component, the type of cause (under- or over-steering, etc.) is detected and an appropriate neural network estimates the variable. Different types of loops can be implemented: slip or torque, or a combination of both. The latter case gives the most convincing results. This is explained by the fact that the torque loop allows the control of torque despite the variations in the parameters of the servovalve and the brake and, in particular despite the state of the brake pads and the working temperature. As with a classic ABS, the slip loop helps to come closest to the optimum slip of the tyre, which is the maximum of Pacejka's representation curve. The general architecture of the IBS control system with the slip control loop and the torque control loop is given in Fig. 7.

The classic algorithms of the pole-placement type have been implemented, tested and validated. However, previous studies also highlighted performance obtained through simulation in the case of high-level control, such as preprogrammed, adaptive or fuzzy control. Chamaillard has widely described these algorithms (Chamaillard et al., 1994).

The software programme is directly tested with an electronic command box connected with a 4-wheel braking simulator. The electronic command box is linked to the development PC, which allows easy parametrization and the immediate analysis of the results.

\section{Results}

At the present time, a great number of tests have been carried out on the rolling bench under realistic conditions and the first vehicle prototypes allowed tests in various weather conditions as well as on different road surfaces that are representative of any real use conditions. The results obtained with the vehicles are promising and the development process is in an intensive phase. The results obtained on the bench allow reproducible conditions that cannot be obtained on an open road. The results obtained in this way are summed up in Figs. 8 and 9. Fig. 8 shows the braking torque, the vehicle speed, the wheel speed and the braking pressure in a rather violent braking phase on a dry road from a $100 \mathrm{~km} / \mathrm{h}$ speed to a complete stop. It must be noted that slip shows remarkable stability which can only be reached through the double loop regulation for torque and slip. It must also be noted that a pressure increase is necessary for efficient stability of the torque. As for the slip loop only, it sometimes tends to become unstable in the form of a limit cycle, as can be observed both on the bench and on the vehicle for all types of braking systems.

Fig. 9 shows the curve of a more realistic situation. The first step represents a braking manoeuvre on a descend, followed by a brake release and finally a sharp braking phase on a horizontal surface.

The results of this new system have been compared with those of a classic ABS. The comparison clearly shows that the system behaves very well. The first results seem to reveal slightly shorter braking distances for the IBS (a few percent for the best cases; this may seem minimal, but it may represent a few meters at high speeds), but as the differences are relatively small, other finer and more accurate tests are being carried out. Indeed, only comparable things can be compared on the basis of a protocol of tests that are robust against the numerous possible disturbances: road surface, weather conditions, temperature, etc.

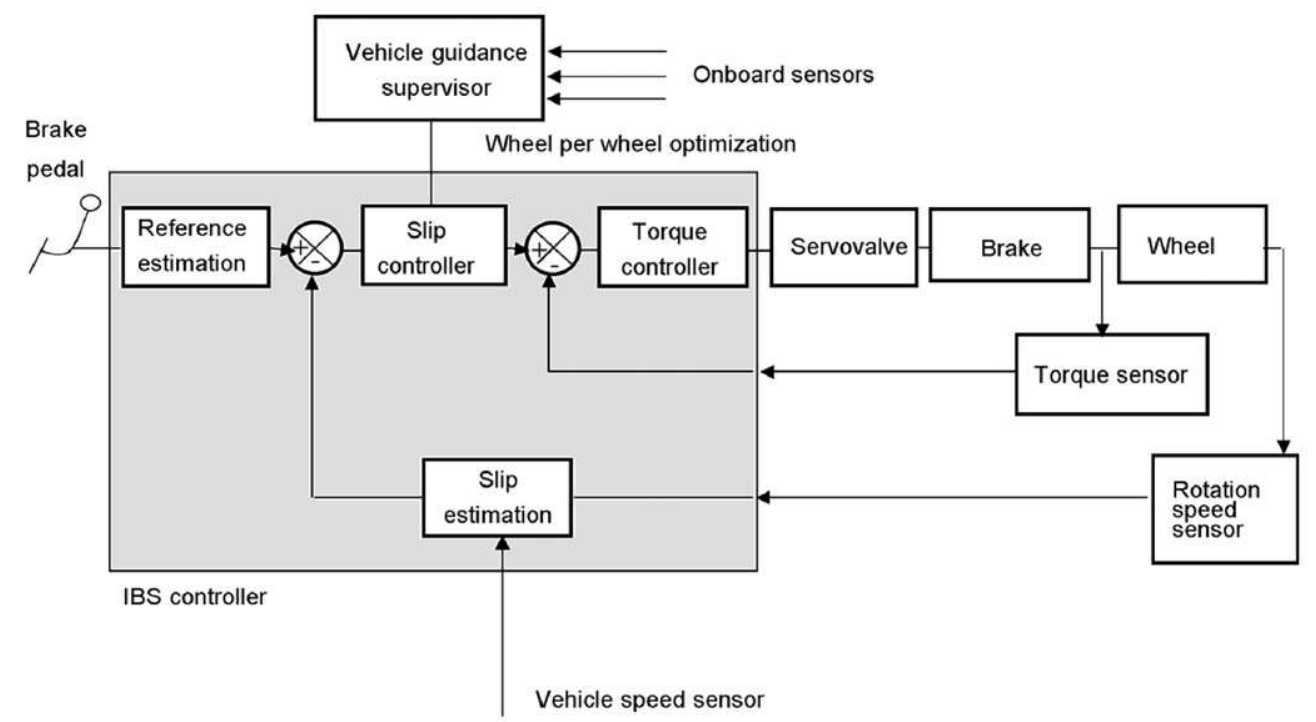

Fig. 7. Control architecture of the intelligent brake system. 


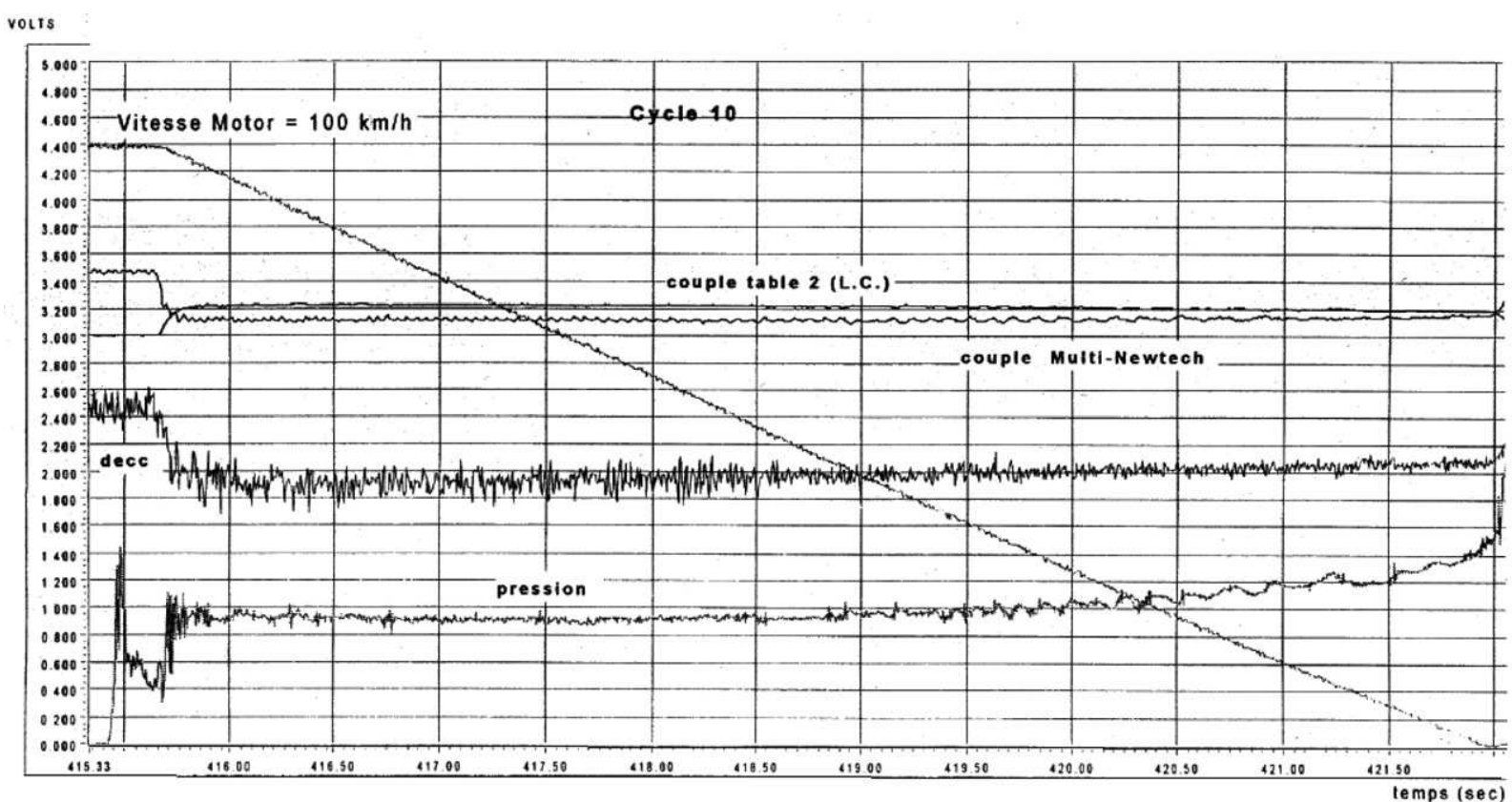

Fig. 8. Braking curves on the test bench (in good conditions).

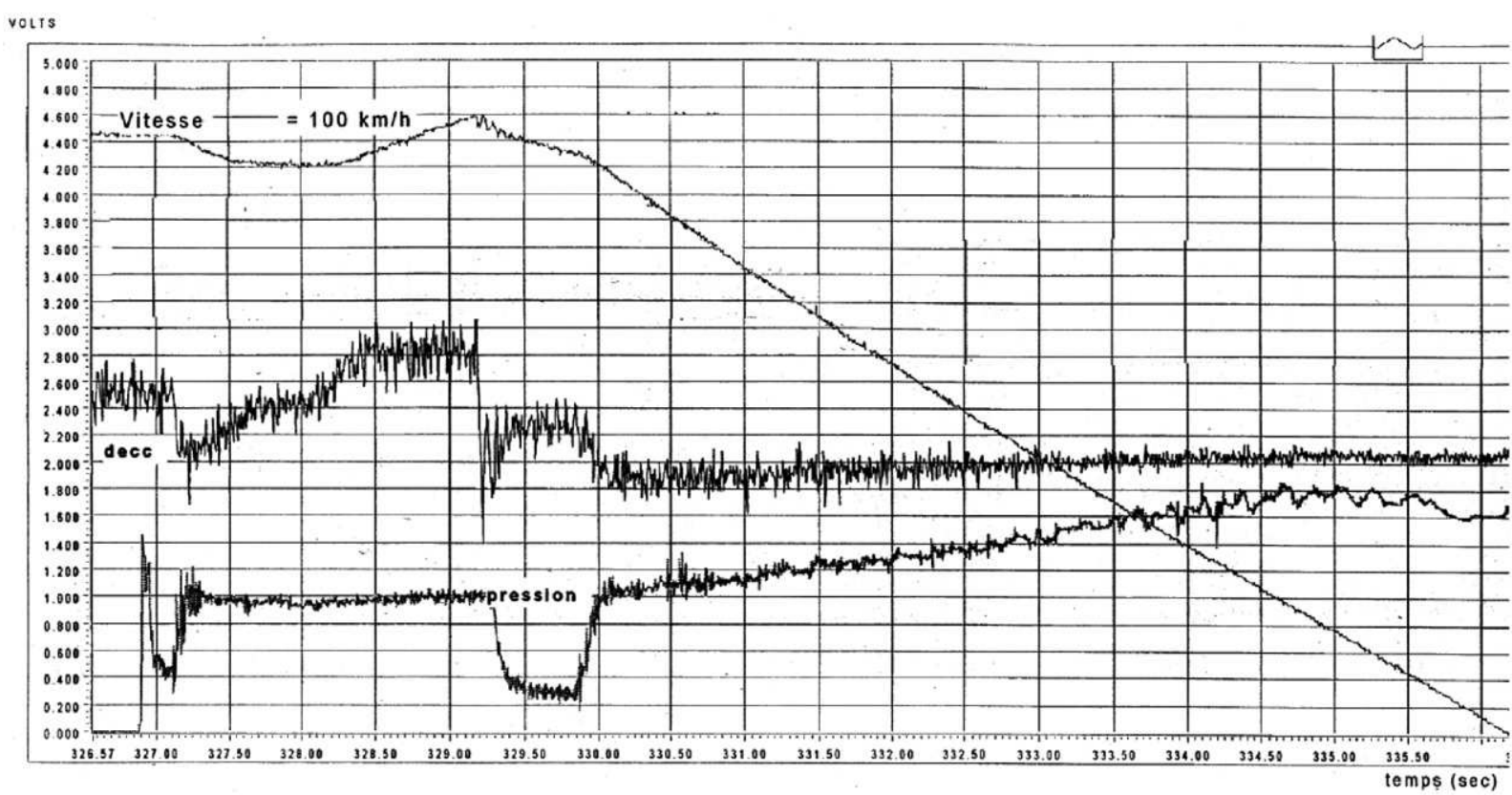

Fig. 9. Braking curves in realistic conditions.

\section{Conclusion}

The studies presented in this paper highlight the benefits of the mechatronic design of a complex system such as a regulated braking system for motor vehicles. All the components have been questioned and rethought. The first prototypes gave promising functioning results and manufacturing should be possible in a near future. It is interesting to note the remarkable stability of deceleration which can only be obtained with the double feedback loop for torque and slip. The whole system is widely open and can work with various brakes, various sensor and actuator solutions, and various types of control algorithms. It must also be mentioned that the different subsystems - such as sensors, actuators, etc-have found other applications since they were 
designed. This new type of braking system offers highly interesting development possibilities and is particularly adapted for new strategies, such as wheel by wheel braking, behaviour control, active braking, etc.

\section{References}

Chamaillard, Y., Gissinger, G. L., \& Menard, C. (1994). Braking regulation of a vehicle, application and comparison of control algorithms of unstable or pseudo-stable fast systems. World Congress SAE Detroit USA—02/94 SAE Paper 940837.

Gissinger, G. L., Voit, M., \& Chamaillard, Y. (1996). Eine komplette Strategie zur Entwicklung von Fahrzeugelementen durchgeführt am Beispiel einer Bremsregelung. Automatisierungs-technik, Special edition Automotive Control 5/96, 201-207.
Isermann, R. (1996). Mechatronic systems - with applications for cars. 13th World Congress of IFAC, Vol Q 8b021, July 96 (pp. 35-40). San Francisco.

Pacejka, H. B., \& Sharp, R. S. (1991). Shear force developments by pneumatic tires in steady-state conditions: A review of modeling aspects. Vehicle Systems Dynamics, 20, 121-176.

Perronne, J. M., Renner, M., \& Gissinger, G. L. (1994). On line measurement of braking torque using a strain sensor. World Congress SAE Detroit USA—02/94 SAE Paper 940333.

Porcel, A., Runde, C., Basset, M., \& Gissinger, G. L. (1998). Neurofuzzy approach to real time total velocity vector estimation of a passenger car covering critical situations. AAC IFAC Workshop Proceedings, 03/1998 (pp. 29-36). Loudonville, USA,

Richalet, J. (1991). Pratique de l'identification; Traité des nouvelles Technologies. Hermès 1991.

Stemmelen, T., Gissinger, G. L., \& Menard, C. (1996). Bond graph modeling of a multipurpose servovalve-Automotive applications. SAE’96, Detroit Michigan, No. 960995, 26/29. 